\author{
Anderson, William Jr, JL Anderson, CS Thaxton, CM Babyak (2010) Changes in stream \\ temperatures in response to restoration of groundwater discharge and solar heating in a \\ culverted, urban stream, Journal of Hydrology 393:309-320, doi:10.1016/ \\ j.jhydrol.2010.08.030. Version of record available from Elsevier [ISSN: 0022-1694], [DOI: \\ 10.1016/j.jhydrol.2010.08.030]
}

\title{
Changes in stream temperatures in response to restoration of groundwater discharge and solar heating in a culverted, urban stream
}

\author{
A B S T R A C T
}

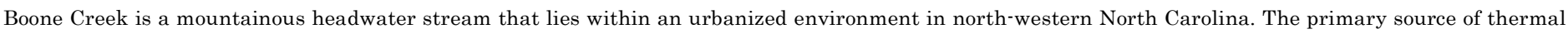

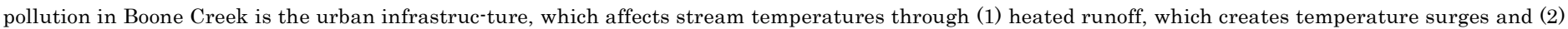

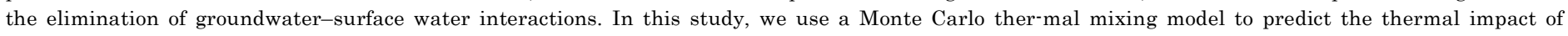

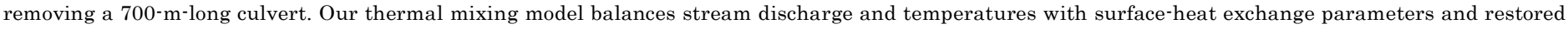

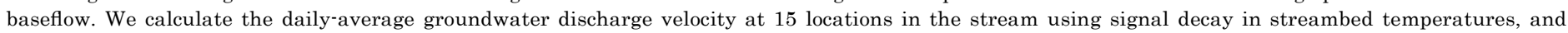

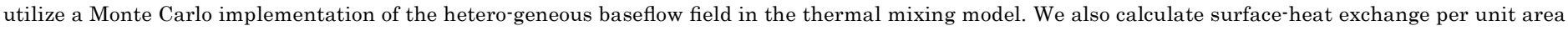

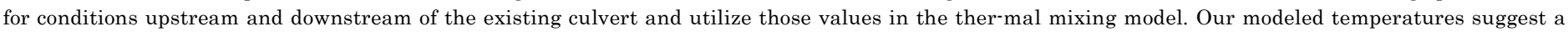

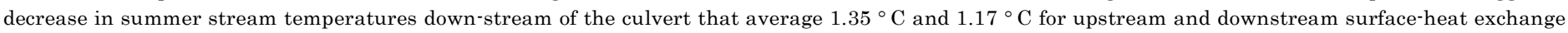

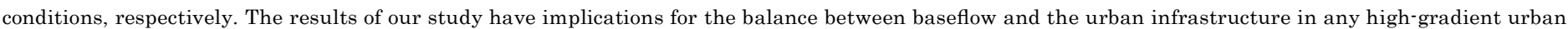
stream that experiences similar ther-mal effects.

\section{Introduction}

Stream temperature is an important water quality parameter for evaluating the health of stream habitat for temperature-dependent freshwater populations. It is especially critical to the understanding of stream temperature dynamics in urban areas, where water temperatures are influenced by many factors. Primary controls on stream temperature are riparian vegetation, groundwater-surface water interactions, and stream width, many of which are reduced or eliminated in urban settings, especially in culverted streams (LeBlanc et al., 1997). The construction of culverts reduces groundwater-surface water interactions, including baseflow, thereby removing a potential buffer of stream temperatures in gaining streams. Webb et al. (2008) provide a comprehensive overview of modern stream temperature studies while summarizing important findings relating stream temperature to (1) atmospheric forcing, (2) anthropogenic forcing, and (3) groundwater forcing.

Studies of atmospheric forcing effects on stream temperature primarily focus on equilibrium temperature (Mohseni and Stefan,
1999; Bogan et al., 2003; Caissie et al., 2005), with some studies solving directly the heat budget equation using a range of meteorological parameters to predict stream temperatures (Sinokrot and Stefan, 1993; Caissie et al., 2007). Stochastically-based empir-ical models in the literature analyze the cumulative effects of atmospheric forcing (Bogan et al., 2006) with most focusing on direct air-temperature/stream-temperature relationships (Caissie et al., 1998, 2001; O'Driscoll and DeWalle, 2006). Groundwater forcing in the form of baseflow plays a moderating role in thermal oscillations within streams and streambeds, especially in small headwater streams where baseflow may be a large component of total stream discharge (Bogan et al., 2003).

Streambed temperature time series are an effective natural tracer for detecting the rate and direction of groundwater movement and, thus, are a primary method for measuring surface watergroundwater interactions (Hatch et al., 2006). Streambed temperature measurements have been used to determine areas of maximum and minimum discharge within a stream reach (Conant, 2004), to develop a field-scale analytical solution for determining groundwater discharge rates (Schmidt et al., 2007), and to quantify groundwater flow in the vicinity of stream barriers, such as natural and constructed dams (Fanelli and Lautz, 2008). All 
of these studies describe the spatially heterogeneous role of groundwater discharge in stream-aquifer interactions. Anderson (2005) provides a detailed overview of the use of temperature to delineate surface-groundwater exchange, which has a long presence in the literature.

In an effort to better understand the interplay between various forcing mechanisms, we use a thermal mixing model to calculate the thermal energy balance of an urban stream (Becker et al., 2004). The study reach includes a $700 \mathrm{~m}$ culverted reach that re-stricts baseflow interaction and limits atmospheric interaction with the stream. The thermal mixing model that we use in this pa-per predicts stream temperatures assuming the removal and restoration of the culverted reach. We hypothesize that stream temperatures will be relatively unchanged with the removal of the culvert because increased surface-heat exchange will be offset by restored baseflow to the stream. We test this hypothesis with a thermal mixing model that predicts daily average stream temperatures by combining estimated daily-average groundwater discharge, observed stream discharge, and modeled atmospheric heat exchange.

\section{Site description}

The study area is a $1.5 \mathrm{~km}$ reach of Boone Creek, a mountainous headwater stream that flows through Boone, North Carolina and Appalachian State University (Fig. 1). The stream channel averages
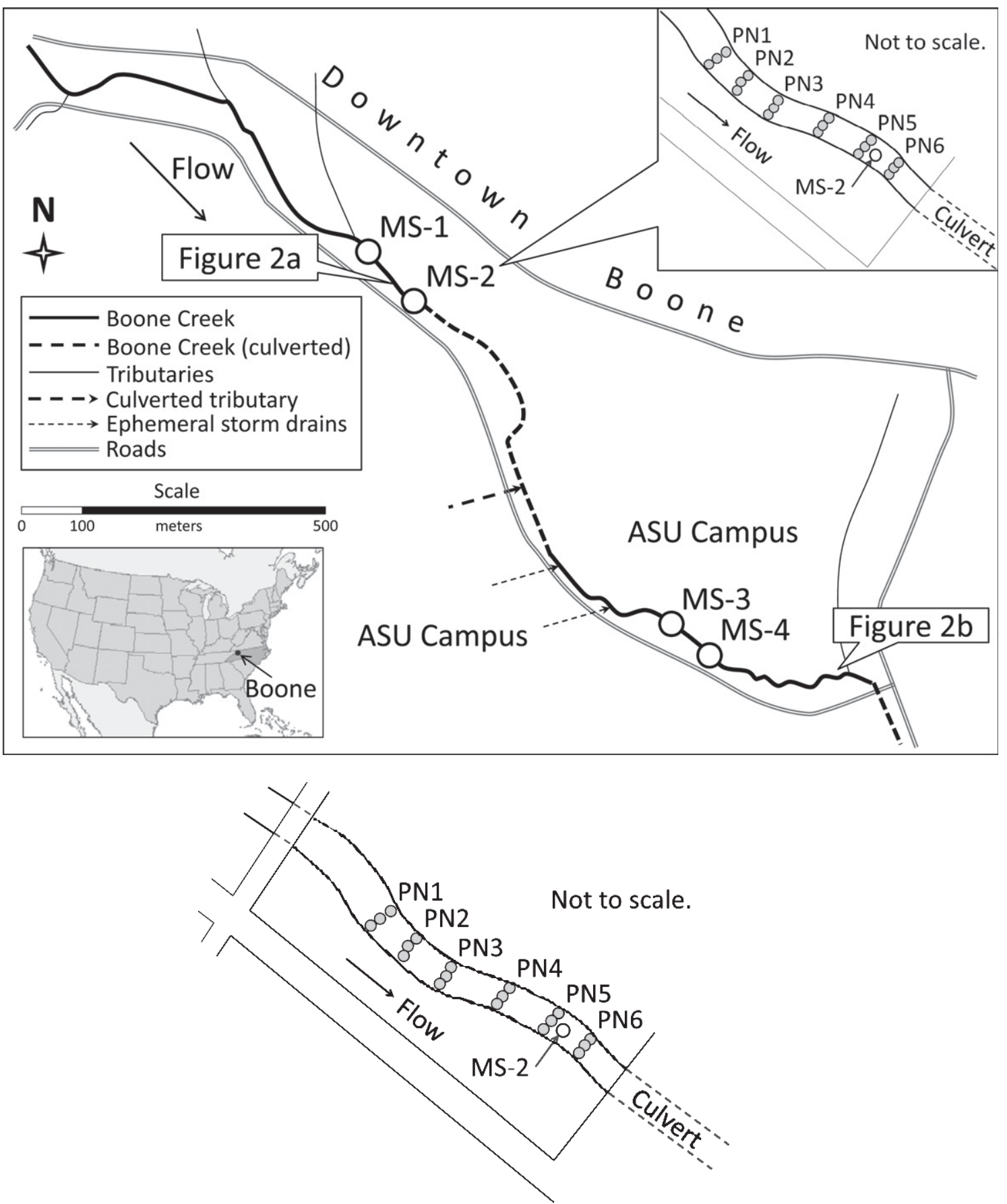

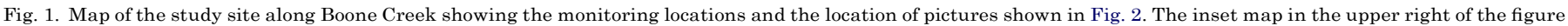

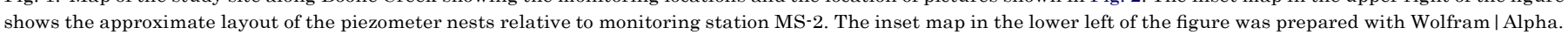


$2.8 \mathrm{~m}$ in width and $20 \mathrm{~cm}$ in depth and loses approximately $30 \mathrm{~m}$ of elevation over the $1.5 \mathrm{~km}$ study reach. Although the stream has a moderate gradient, it is fed by tributaries coming off of the adjacent mountains that lose up to $200 \mathrm{~m}$ of elevation per kilome-ter of stream. Extensive urbanization along the main stem of Boone Creek limits natural, undisturbed conditions and includes limited riparian vegetation, incised channels, and extensive impervious areas in the form of roads, parking lots, and buildings. Storm runoff drains directly into the stream from parking lots, buildings, and roads with the aid of more than 70 drainage pipes. Rapid runoff during summer storms transfers the heat stored in the urban infrastructure directly to the stream in minutes (Nelson and Palmer, 2007). Three summers of stream temperature monitoring of Boone Creek reveals up to 40 instances per summer in which temperatures rise more than $1{ }^{\circ} \mathrm{C}$ within 15 min (Anderson et al., 2007). In addition to rapid temperature fluctuations, approximately $700 \mathrm{~m}$ of the stream lies in a culvert beneath a series of parking lots and buildings, effectively dividing Boone Creek into two streams. Conditions upstream of the culvert contain approximately $50 \%$ riparian cover and few outfall pipes (Fig. 2a); conditions downstream are more extensively urbanized, lacking riparian vegetation and containing a majority of the outfall pipes (Fig. 2b).

\section{Methods and data}

\subsection{Stream discharge and temperature data}

We collected stream temperature data at 15 -min intervals between June 1, 2008 and August 31, 2008 at the four monitoring stations (MS-1 through MS-4) shown in Fig. 1. We also measured stream stage at 15 -min intervals at monitoring sites MS-2 and MS-3. Stream discharge was manually measured at monitoring stations MS-2 and MS-3 during known stream stage values using a digital water velocity meter. Twenty manual measurements were made at monitoring stations MS-2 and MS-3. Higher discharge measurements were possible at monitoring station MS-3 because of a bridge, which enabled access during high flows. Monitoring station MS-2 was not accessible during high flow events; therefore, peak manual discharge measurements are lower. We fit power-law curves to stage versus discharge plots, thereby enabling direct computation of discharge from the stage data. After establishing the rating curves, we converted all of the stream stage data to discharge rates.

\subsection{Baseflow analysis}

We installed 18 piezometer nests (six rows by three nests) in the stream reach adjacent to gauging site MS-2 (after Conant,
Table 1

Physical parameters used in the thermal mixing model.

\begin{tabular}{lll}
\hline Parameter & Value & Units \\
\hline Effective thermal diffusivity, $j_{e}$ & $8.1 \times 10-7$ & $\mathrm{~m}^{2} / \mathrm{s}$ \\
Specific heat of saturated streambed materials, $c_{\text {matrix }}$ & 2100 & $\mathrm{~J} /\left(\mathrm{kg}^{\circ} \mathrm{C}\right)$ \\
Specific heat of water, $c_{\text {water }}$ & 4182 & $\mathrm{~J} /\left(\mathrm{kg}^{\circ} \mathrm{C}\right)$ \\
Density of water, $q$ & 1000 & $\mathrm{~kg} / \mathrm{m}^{3}$ \\
\hline
\end{tabular}

2004) on May 31, 2008 and collected data from this date through August 31, 2008 (see inset of Fig. 1). Temperature data were collected at 15 -min intervals by two temperature dataloggers spaced $25 \mathrm{~cm}$ apart in each of the piezometer nests. We lost two of these piezometer nests (PN3-L and PN5-M) due to large storm flows, which ripped them out of the streambed, and the data from another piezometer nest (PN3-M) due to a faulty temperature datalogger, leaving 15 piezometer nests for the entire summer monitoring season.

We combined our temperature time-series data with an analytical solution to quantify baseflow velocities at each of the measurement sites (Hatch et al., 2006). Streambed temperatures and their lagged thermal response to surface conditions can be used to calculate groundwater velocities in both gaining and losing streams as long as the vertical separation is known (Hatch et al., 2006; see also Keery et al., 2007, for further discussion of a similar method). Daily velocities may be calculated for a given time series of streambed temperatures using either (1) the ratio of decreasing amplitude in the daily streambed temperature sig-nal with depth or (2) the phase shift in the timing of the peak measured temperature with depth. A recent study demonstrates that the amplitude ratio is more reliable than phase shift for cal-culating daily groundwater discharge velocities under non-ideal field conditions (Lautz, 2010). We use this method in our calculations.

After filtering our streambed temperature data by subtracting a 24 -h running average from the measured data, we use the amplitude ratio (Hatch et al., 2006) to calculate velocity with

$$
v=\frac{2 \kappa_{e}}{\Delta z} \ln A_{r}+\sqrt{\frac{\alpha+v^{2}}{2}},
$$

where

$$
\alpha=\sqrt{v^{4}+\left(\frac{8 \pi \kappa_{e}}{P}\right)^{2}} .
$$

In (1) and (2), $v$ is the rate of penetration of the thermal front $(\mathrm{m} / \mathrm{d})$, $j_{e}$ is the effective thermal diffusivity $\left(\mathrm{m}^{2} / \mathrm{s}\right), \mathrm{D} z$ is the distance
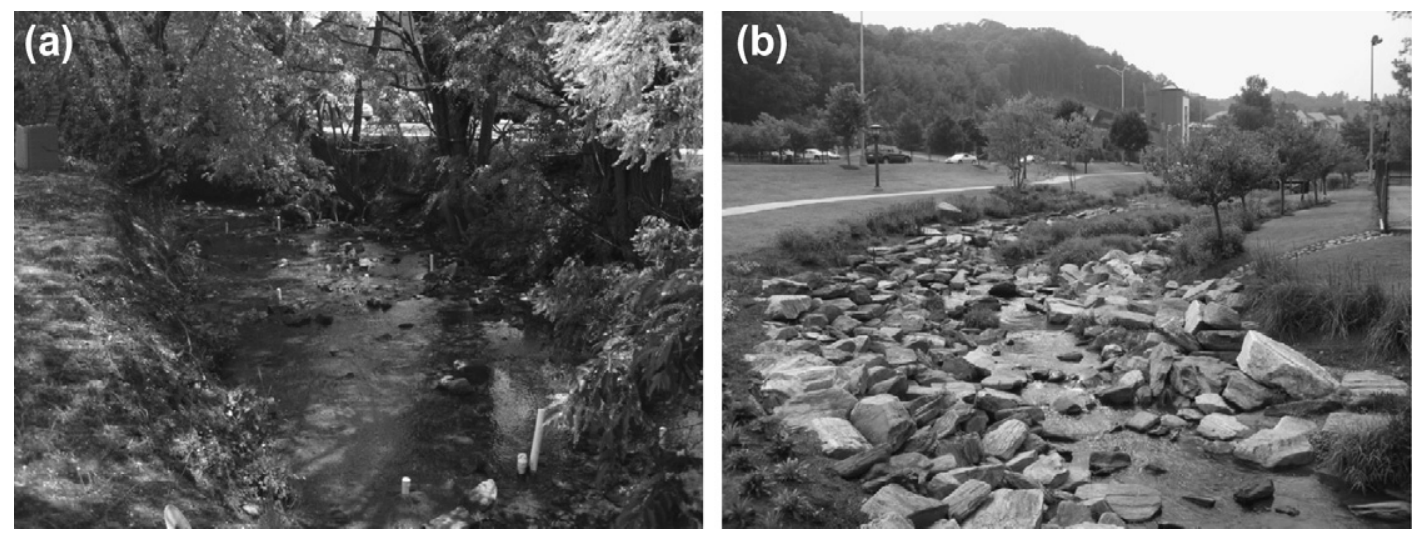

Fig. 2. Pictures of Boone Creek (a) upstream of the culvert near monitoring station MS-2, where riparian vegetation still exists and (b) downstream of monitoring station MS3 , where riparian vegetation has been removed in favor of ornamental plants and large stones. Note the streambed piezometer nests in (a). 
between temperature measurements $(\mathrm{m}), A_{r}$ is the amplitude ratio, taken to be the ratio of amplitude of the deep signal to that of the shallow signal, and $P$ is the period of the oscillation, taken in this study to be 1 day. These velocities can be converted to fluid velocity by multiplying by the ratio of the saturated streambed material's heat capacity to that of the fluid (Hatch et al., 2006). The interrelation between (1) and (2), in which velocity is found on both sides of (1), requires that fluid velocities be calculated with an iterative process. The thermal parameters used to calculate stream velocities, and subsequent thermal properties used in the mixing model, are shown in Table 1.

\subsection{Monte Carlo thermal mixing model}

Fig. 3a shows the conceptual model of existing conditions in the vicinity of the culverted stream (see Becker et al., 2004, for the use of a similar methodology). The stream enters the culvert at monitoring station MS-2. A culverted tributary joins the culverted stream from the west near the end of the culvert. The existing barrier eliminates direct solar heating and allows muted interaction with the atmosphere through surface-heat exchange processes such as latent heat of evaporation and latent heat of condensation (see Mohseni and Stefan (1999), for a detailed analysis of these parameters), while restricting the buffering influence of groundwater, which cools the stream during summer months and warms the stream during winter months. The stream interacts with groundwater upon exiting the culvert and is also affected by surface-heat exchange in this region before reaching monitoring site MS-3, 920 $\mathrm{m}$ downstream. The energy balance in the existing stream between the two monitoring stations is related by

$$
\begin{aligned}
& (\rho c) Q_{\mathrm{MS}-2} T_{\mathrm{MS}-2}+(\rho c) Q_{\text {trib }} T_{\text {trib }}+S H E_{\text {culvert }} A_{\text {culvert }}+S H E_{\text {natural }} A_{\text {natural }} \\
& \quad+(\rho c) Q_{\mathrm{gw}} T_{\mathrm{gw}}=(\rho c) Q_{\mathrm{MS}-3} T_{\mathrm{MS}-3}
\end{aligned}
$$

where $q$ is the density of water $\left(\mathrm{kg} / \mathrm{m}^{3}\right), c$ is the specific heat of water $\left(\mathrm{J} /\left(\mathrm{kg}{ }^{\circ} \mathrm{C}\right)\right), Q$ is stream discharge $\left(\mathrm{m}^{3} / \mathrm{d}\right), T$ is temperature $\left({ }^{\circ} \mathrm{C}\right)$, $S H E$ is surface-heat exchange $\left(\mathrm{J} / \mathrm{m}^{2} / \mathrm{d}\right)$, and $A$ is the surface area of the stream reach (Becker et al., 2004). Subscripts MS-2 and MS-3 in (3) refer to the monitoring locations, $g w$ represents groundwater, trib represents stormwater influx from the culverted tributary within the existing culvert, and culvert and natural represent culverted and open stream reaches, respectively.
We have assumed the physical properties shown in Table 1 and have measurements of stream discharge and temperature at monitoring sites MS-2 and MS-3. We use those data to approximate baseflow and culverted tributary flow conditions, assuming a temperature for the culverted tributary water equal to that measured at MS-2 and using local measurements of groundwater temperature. The only unknown in (3) under existing flow conditions are the two components of $S H E$ in the culvert and in the exposed section of stream. We feel justified in assuming that the temperature of the culverted tributary is the same as that measured at monitoring station MS-2 given that it drains a sub-catchment with similar riparian cover and levels of urbanization. The influence of the approximated values in (3) are evaluated in a sensitivity analysis (see Sections 3.4 and 4.4).

Hypothetical restored conditions, which will expose the stream to atmospheric and groundwater interactions, will allow full thermal mixing and will likely produce different stream temperatures than are currently being measured at MS-3 (Fig. 3b). With stream restoration there will be only one component of SHE and groundwater will interact with the stream along the entire reach. The energy balance equation for the restored system is

$$
\begin{aligned}
& (\rho c) Q_{\mathrm{MS}-2} T_{\mathrm{MS}-2}+(\rho c) Q_{t r i b} T_{\text {trib }}+S H E \cdot A+(\rho c) Q_{\mathrm{gw}} T_{g w} \\
& \quad=(\rho c) Q_{\mathrm{MS}-3} T_{\mathrm{MS}-3}
\end{aligned}
$$

(Becker et al., 2004). As with current conditions, the only unknown components of this equation are $S H E$ and baseflow because we can approximate culverted tributary discharge and temperature based on mass balance and the use of MS-2 stream temperatures. In order to implement the energy balance model in (4), we must then answer two questions: (1) how do we determine the SHE component of the energy balance equation in (4)? and (2) how accurate is it to extrapolate groundwater discharge velocities from the study reach described in Section 3.2 to the hypothetically restored reach of Boone Creek?

Because there are two components of $S H E$ under the existing culverted conditions, we cannot use (3) to calculate $S H E$ for the restored model; however, we do have two other monitoring stations, MS-1 and MS-4, at which we measure stream temperature. Although we do not measure stream discharge at those locations, we can approximate their values because there are no tributaries between moni- (a)

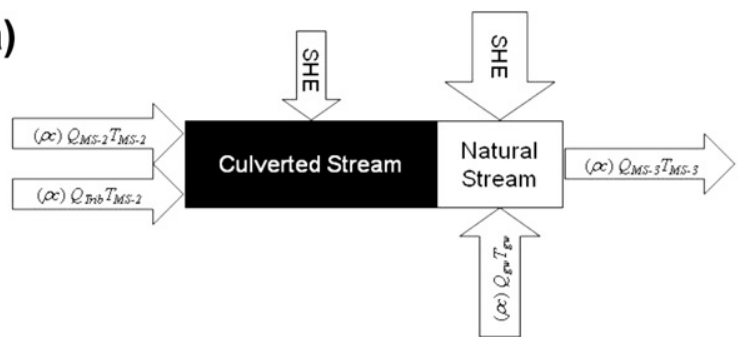

(b)

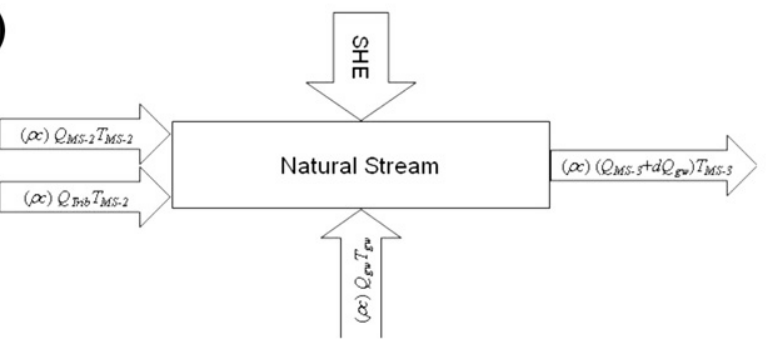

(c)

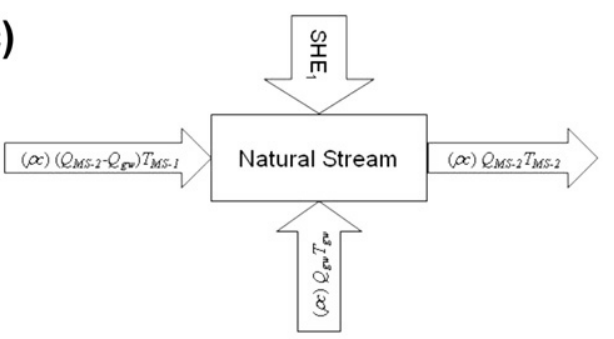

(d)

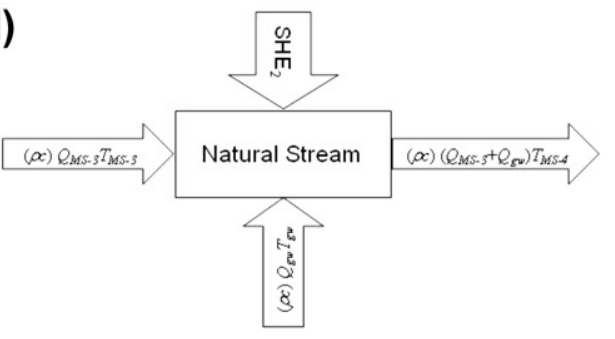

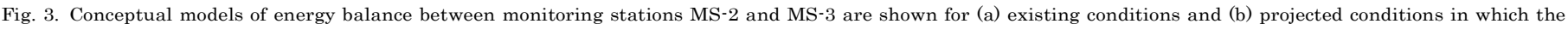

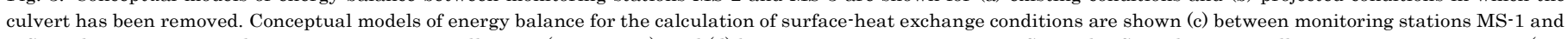

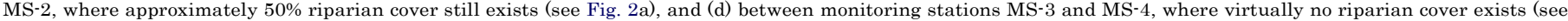
Fig. 2b). 
toring stations MS- 1 and MS- 2 or between MS- 3 and MS-4, leaving only a groundwater component. Between monitoring stations MS-1 and MS-2 (Fig. 3c), the energy balance equation is

$$
(\rho c)\left(Q_{\mathrm{MS}-2}-Q_{\mathrm{gw}}\right) T_{\mathrm{MS}-1}+(\rho c) Q_{\mathrm{gw}} T_{\mathrm{gw}}+\mathrm{SHE}_{1} A_{1}=(\rho c) Q_{\mathrm{MS}-2} T_{\mathrm{MS}-2},
$$

where $Q_{g w}$ is the component of groundwater discharge between the two stations, $S H E_{1}$ is the surface-heat exchange along that reach, and $A_{1}$ is the area of the reach (Becker et al., 2004). We calculate stream discharge at monitoring station MS-1 by reducing measured discharge at monitoring station MS-2 by the approximated amount of baseflow that occurs between the two sites. Likewise, between monitoring stations MS-3 and MS-4 there are no tributaries and all additions to stream discharge occur as baseflow. The energy balance equation between these two monitoring sites (Fig. 3d) is

$(\rho c) Q_{\mathrm{MS}-3} T_{\mathrm{MS}-3}+(\rho c) Q_{\mathrm{gw}} T_{\mathrm{gw}}+\mathrm{SHE}_{2} A_{2}$

$$
=(\rho c)\left(Q_{\mathrm{MS}-2}+Q_{\mathrm{gw}}\right) T_{\mathrm{MS}-4},
$$

where $Q_{g w}$ is again the component of baseflow between the two stations, $S H E_{2}$ is the surface-heat exchange along that reach, and $A_{2}$ is the area of the reach (Becker et al., 2004).

We employ the Monte Carlo thermal mixing model to predict stream temperatures at monitoring station MS-3 assuming the removal of the culvert and restored groundwater-stream interaction. In order to make this assumption, however, we must extrapolate our modeled groundwater discharge rates from the monitored reach surrounding monitoring station MS-2 to the hypothetically restored portion of the stream. This is perhaps the limiting factor

Table 2

Parameters used in the sensitivity simulations.

\begin{tabular}{llcll}
\hline Parameter & $v_{g w}(\mathrm{~m} / \mathrm{d})$ & $T_{g w}\left({ }^{\circ} \mathrm{C}\right)$ & $T_{\text {trib }}\left({ }^{\circ} \mathrm{C}\right)$ & SHE \\
\hline Base simulation & Variable & 10.6 & $T_{\mathrm{MS}-2}$ & Variable \\
Increase & $v_{g w}+2 S T D E V$ & 9.0 & $T_{\mathrm{MS}-2}+2$ & $2.0^{*} \mathrm{SHE}_{1}$ \\
Decrease & $v_{g w}-2 S T D E V$ & 12.0 & $T_{\mathrm{MS}-2}-2$ & $0.50^{*} \mathrm{SHE}_{1}$ \\
\hline
\end{tabular}

in our methodology; however, we think that it is defensible in light of several factors. The hypothetically restored section begins immediately downstream of the monitored reach and prior to culverting likely comprised similar streambed materials as those in the study reach. In fact, streambed materials along the entire $1.5 \mathrm{~km}$ study length show similar grain-size distributions and ranges of variation based on unpublished analyses. In addition, we expect the regional gradient driving baseflow to be similar along the entire $1.5 \mathrm{~km}$ study of Boone Creek, which along its length lies between two parallel ridges.

In order to more accurately reflect the potential heterogeneity of groundwater-surface water interactions in Boone Creek, and to account for potential errors in extrapolating from the detailed streambed study reach to the hypothetical restored reach, the Monte Carlo thermal mixing model samples randomly from a Gaussian distribution of the daily mean and standard deviation of the groundwater discharge velocities that we have computed (Hatch et al., 2006). We assume with this method that the baseflow variations arise from streambed material heterogeneity and local variations in gradient; however, the Monte Carlo sensitivity simulations also suggest upper and lower limits for predicted downstream temperatures should the hypothetical restored reach have a higher or lower mean groundwater discharge than the detailed study reach. We utilize 500 realizations per day and perform our simulations using both surface-heating conditions, $S H E_{1}$ and $S H E_{2}$. Please note that we explore the effect on predicted down-stream temperatures of higher and lower mean groundwater dis-charge rates with sensitivity analyses, which are described in the next section.

\subsection{Monte Carlo thermal mixing model sensitivity}

The mixing model utilizes several parameters that have been approximated, including (1) the calculations of surface-heat exchange upstream and downstream of the culverted reach, which utilize approximations of baseflow to compute stream discharge at monitoring stations MS- 1 and MS-4; and (2) the temperature
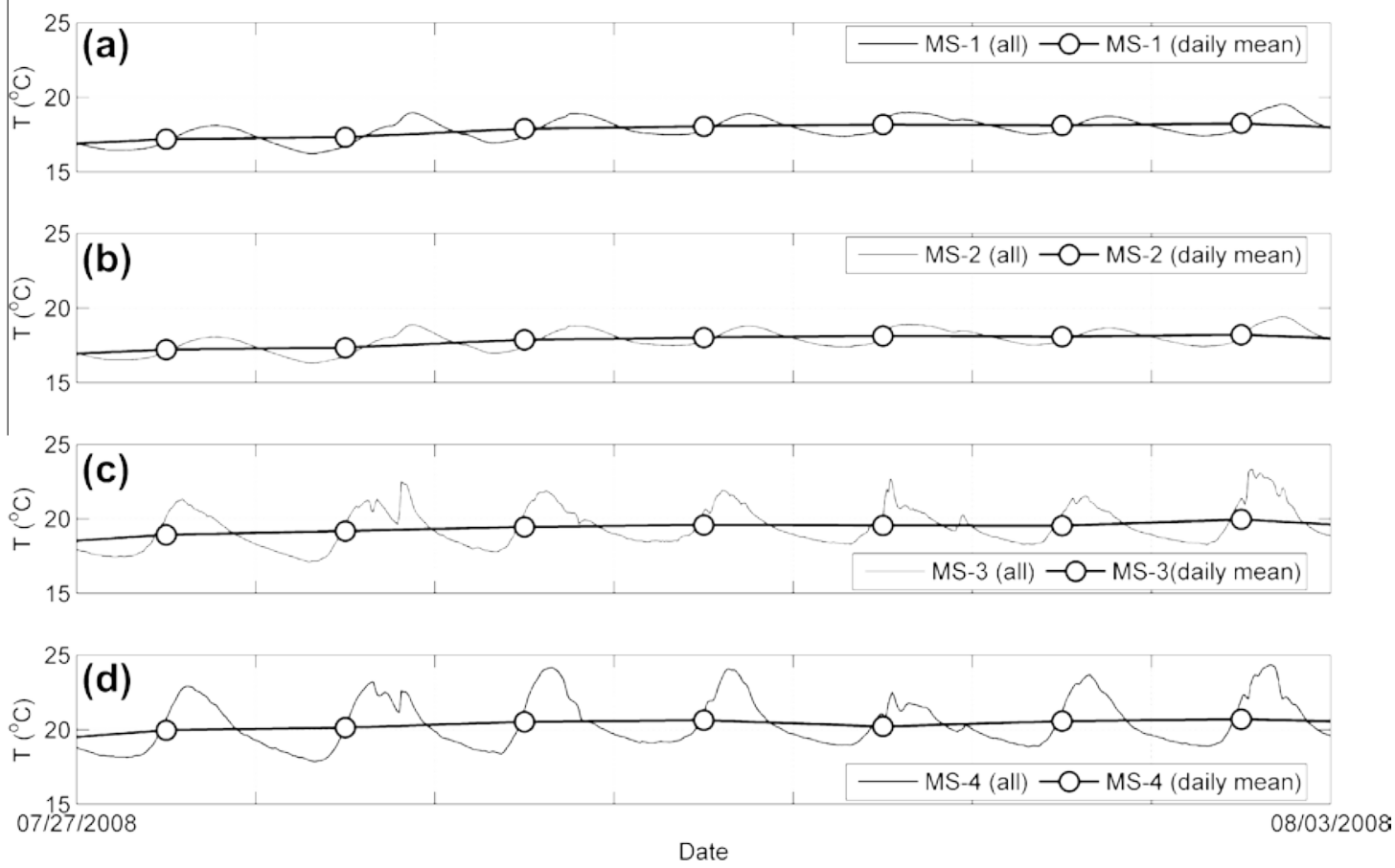

Fig. 4. Daily mean (thick lines with white circles) and 15-min (thin lines) stream temperature data as measured at the four monitoring stations. We show a week's worth of data (July 27, 2008-August 3,2008) as representative of the entire dataset. 


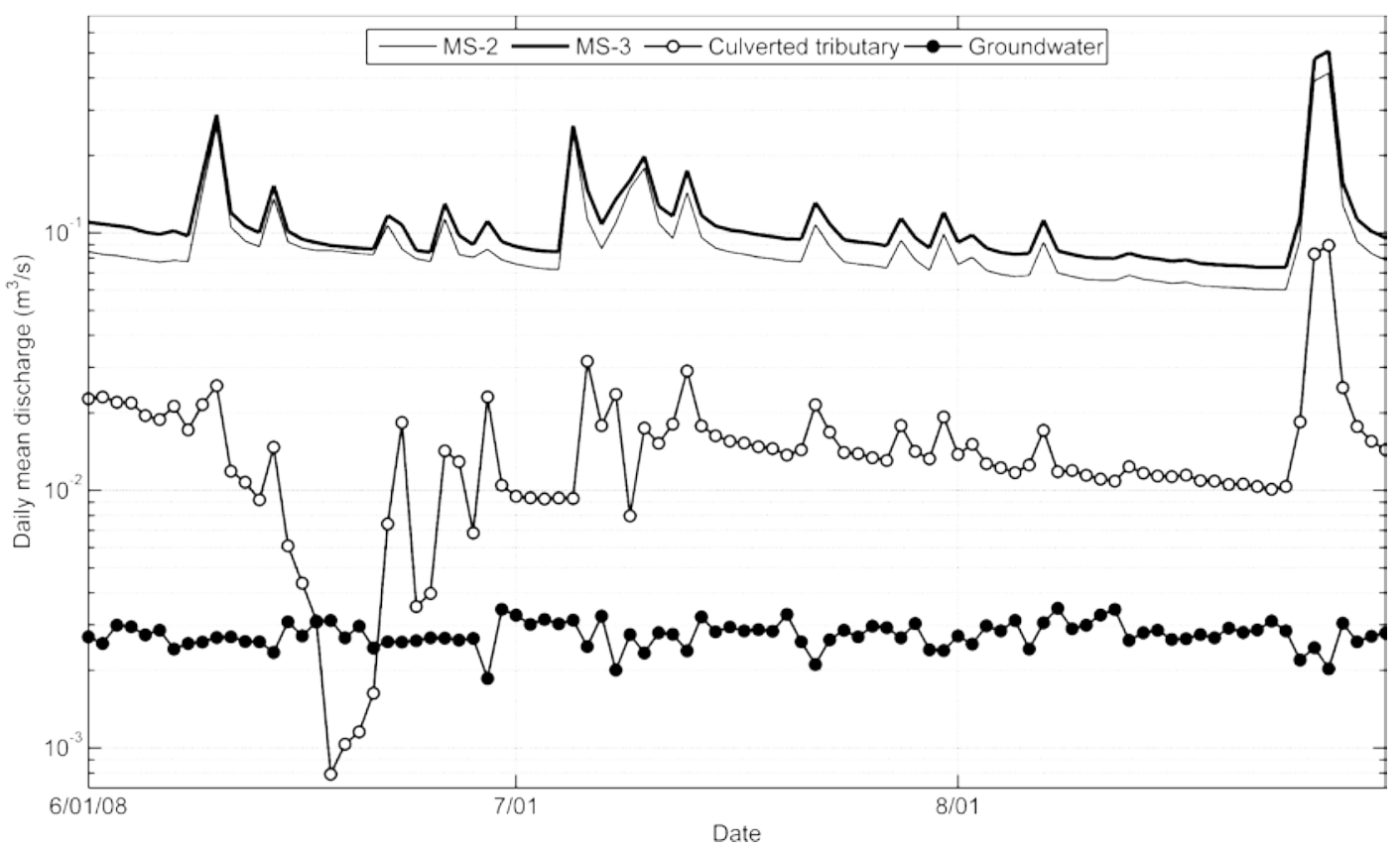

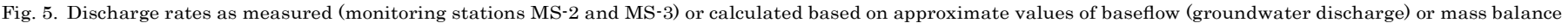
(culverted tributary discharge).

of the tributary stream, which is inaccessible within the culvert. Model sensitivity analyses show the effect that these approximated parameters have on modeled stream temperatures. In each sensitivity simulation, model parameters are held constant while varying only one parameter. All sensitivity simulations are compared to base simulations computed using conditions without the culvert and $S H E_{1}$ surface-heating conditions. Table 2 shows a list of the sensitivity simulations and the parameters that vary in each sensitivity simulation. Groundwater discharge velocities that we calculated (Hatch et al., 2006) were insensitive to changes in physical parameters and are not included in the sensitivity results.
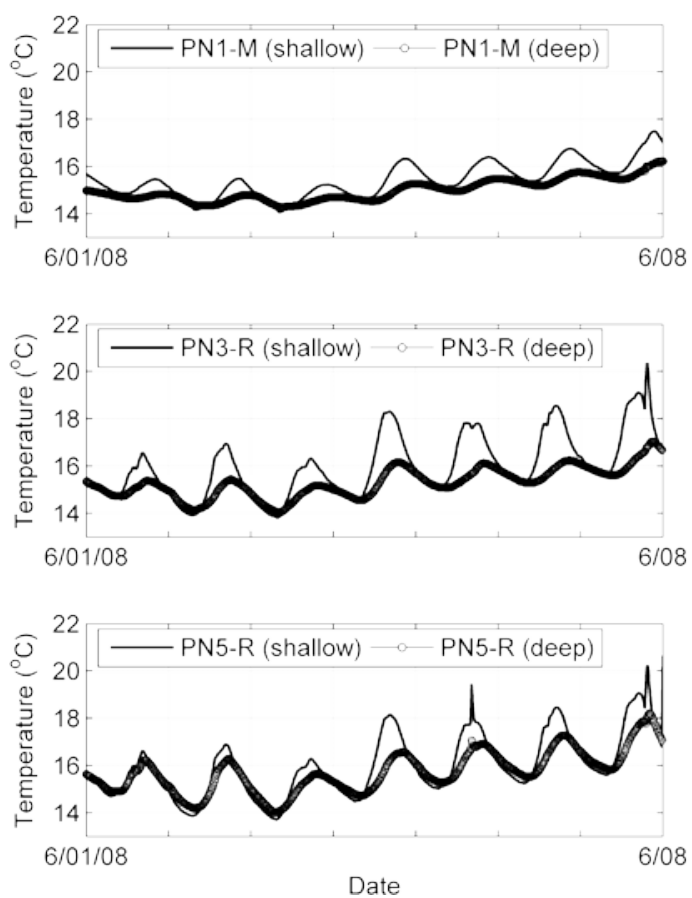

\section{Results and discussion}

\subsection{Stream temperature and discharge}

In general, stream temperatures increase with distance downstream (Fig. 4) as the result of (1) equilibrium temperature effects (Bogan et al., 2003) and (2) the compounding effects of urbanization (Anderson et al., 2007; Nelson and Palmer, 2007; Herb et al., 2008). Groundwater temperatures that we measured in an observation well in the region average $10.6^{\circ} \mathrm{C}$ with minimal oscillation $\left(<0.1^{\circ} \mathrm{C}\right)$. Manual stream discharge measurements ranged from
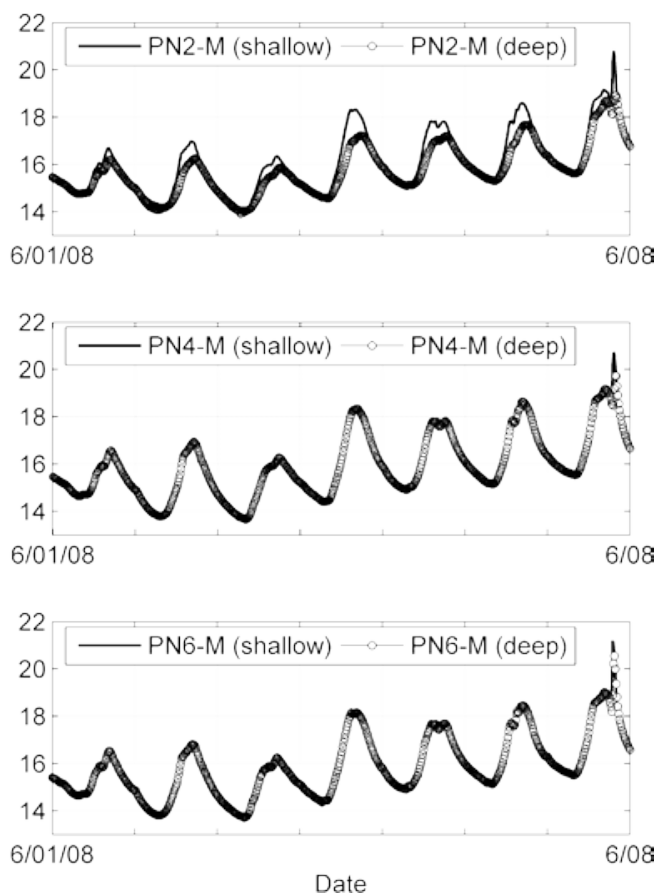

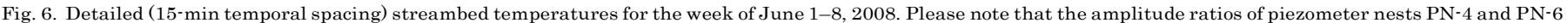
are on the order of 0.9 and are solvable with the Hatch method. 


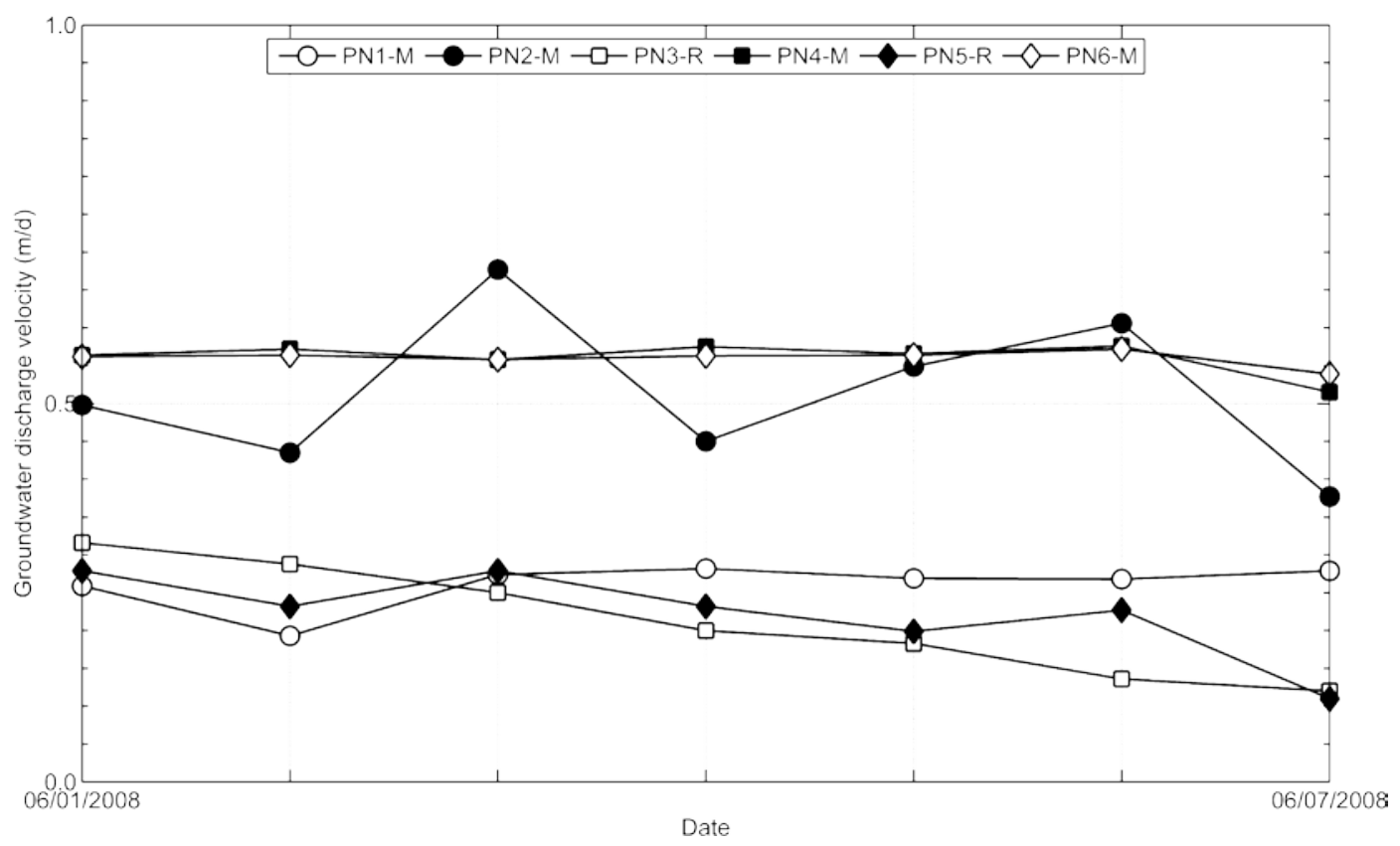

Fig. 7. Groundwater discharge velocities as calculated at the same locations and dates as shown in Fig. 5.

$0.018 \mathrm{~m}^{3} / \mathrm{s}$ to $0.111 \mathrm{~m}^{3} / \mathrm{s}$ and from $0.035 \mathrm{~m}^{3} / \mathrm{s}$ to $0.729 \mathrm{~m}^{3} / \mathrm{s}$ at monitoring stations MS-2 and MS-3, respectively, during the period of measurement. Note that these measurements nicely window the daily mean discharge rates shown in Fig. 5.

Stream discharge at monitoring station MS- 3 is, on average, $16 \%$ larger than it is at monitoring station MS-2. This increase in discharge arises from (1) groundwater discharge between the end of the culvert and monitoring station MS-3 and (2) the culverted tributary inflow (location shown in Fig. 1) to the stream within the existing culvert. We estimate daily mean values of groundwater discharge based on daily mean baseflow velocities and stream area (as discussed in Section 3.2). The remaining difference between stream discharge at monitoring stations MS-2 and MS-3 is the culverted tributary estimate of discharge. We show these estimated values in Fig. 5 to demonstrate their relatively small contribution to total flow. Both of these components are variable; however, in general, the groundwater component of discharge is approximately $3 \%$ of total discharge and the culverted tributary component of discharge is approximately $13 \%$ of total discharge (Fig. 5).

\subsection{Groundwater discharge velocity analysis}

We show a representative sample of streambed temperature data (a week of data collected between June 1 and June 8, 2008)

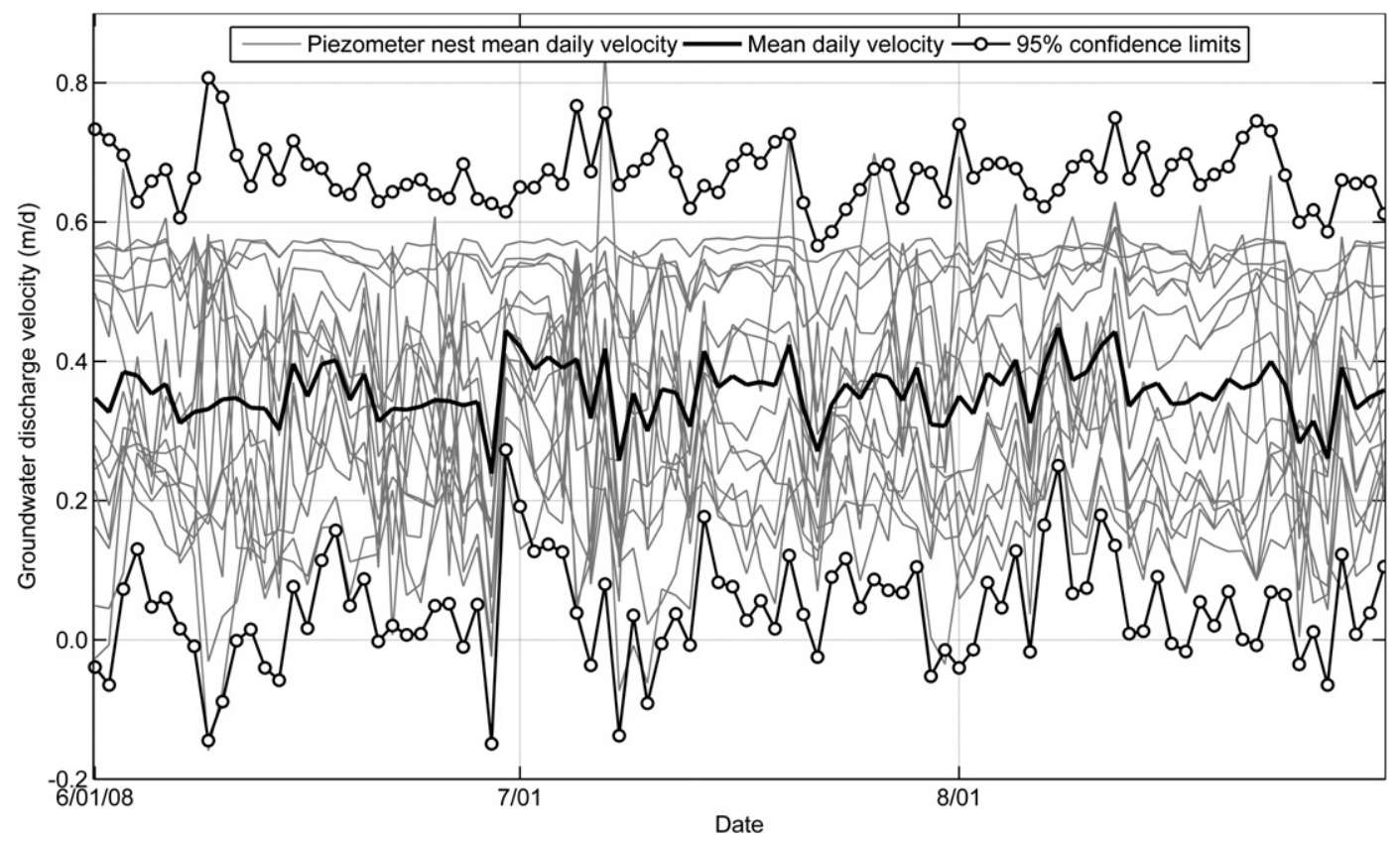

Fig. 8. Baseflow heterogeneity during the duration of Summer 2008. Daily-mean groundwater discharge velocities for the 15 piezometer nests are shown as thin gray lines. Mean groundwater discharge velocities are shown with the thick black line. Ninety-five percent confidence limits are shown as lines with white circles. 
in Fig. 6. We show data from the middle of each row of piezometer nests with the exception of PN3 and PN5, in which we show the piezometer nests from stream right due to the loss of the middle nest. We combined the temperature data from the 15 piezometer nests collected during the summer of 2008 (Fig. 7) with an analytical solution (Hatch et al., 2006) to calculate daily-average groundwater discharge velocities for each piezometer nest in the study reach. We show the results of the velocity calculations in Figs. 7 and 8. We show 1 week of calculated groundwater discharge veloc-ities in Fig. 7 using the same piezometer nests and time frame as Fig. 5. I n Fig. 8, we show all of the groundwater discharge velocities for the Summer 2008 monitoring season. Also shown in Fig. 8 are the daily-mean groundwater discharge velocities and the $95 \%$ confidence limits of our data. The 15 piezometer nests in the streambed produce a wide range of groundwater discharge velocities, with values varying from a maximum of $0.84 \mathrm{~m} / \mathrm{d}$ to a minimum of $-0.16 \mathrm{~m} / \mathrm{d}$ during a high-flow period in which there were re-versed gradients in the streambed. The overall mean groundwater discharge velocity during the period of measurement was $0.37 \mathrm{~m} / \mathrm{d}$, and daily streambed velocity differences between maximum and minimum values ranged from $0.74 \mathrm{~m} / \mathrm{d}$ to $0.29 \mathrm{~m} / \mathrm{d}$. We sample randomly from these daily-mean groundwater discharge velocities and combine them with average stream area to incorporate restored groundwater discharge to the Monte Carlo thermal mixing model.

\subsection{Monte Carlo thermal mixing model}

Calculations with the Monte Carlo thermal mixing model of (4) under the conceptual model of Fig. 3b, in which the culvert has been removed, utilize the inferred groundwater discharge rates based on calculated groundwater discharge velocities, the physical parameters shown in Table 1 , and the two culvert removal surfaceheat-exchange scenarios, $S H E_{1}$ and $S H E_{2}$, that we describe in Section 3.3. These two estimates of surface-heat exchange can be thought of as worst-case and best-case scenarios: culvert removal conditions would likely be similar to downstream conditions immediately following stream restoration, and, with proper planning, would likely move toward upstream conditions as riparian vegetation became established. Thus, the two modeled conditions represent two end members of a surface-heating continuum. Stream temperatures with removal of the culvert would likely fall somewhere within this temperature envelope.

The solution of energy balance Eqs. (5) and (6) to obtain estimates of surface-heat-exchange, $S H E_{1}$ and $S H E_{2}$, are shown in Fig. 9. The effect of surface heating increases through the summer months, reaching a peak in early August before declining for the rest of the summer. Conditions upstream and downstream of the culvert reflect conditions in two completely different streams: one upstream, in which riparian cover reduces the effect of solar radiation, and one downstream, in which riparian cover is virtually non-existent and solar radiation is more dominant (see Fig. 2 for pictures of upstream and downstream conditions). Our calculations also reflect this reality. Surface heating downstream of the culvert, as reflected by $S H E_{2}$ values in Fig. 9 , is on average $41 \%$ larger than conditions upstream of the culvert, as reflected by $S H E_{1}$ conditions.

We perform calculations with both of these surface-heating conditions in the Monte Carlo thermal mixing model in order to predict stream temperatures at monitoring station MS-3 with the removal of the culvert. We show the results of the mixing model in Fig. 10. Fig. 10a shows the results with the surface-heating scenario $S H E_{1}$. Under this scenario, the restoration of $700 \mathrm{~m}$ of groundwater-stream interaction offsets the influence of restored direct solar radiation and predicted stream temperatures decline by a mean of $1.35{ }^{\circ} \mathrm{C}$ with a maximum difference of $1.80^{\circ} \mathrm{C}$ and a minimum difference of $0.73^{\circ} \mathrm{C}$. Under surface-heating scenario $S H E_{2}$ (Fig. 10b), temperatures also decline but at a mean of $1.17^{\circ} \mathrm{C}$ with a maximum difference of $1.62{ }^{\circ} \mathrm{C}$ and a minimum difference of $0.72^{\circ}$ C. We show both temperature predictions and observed temperatures at monitoring station MS-3 in Fig. 10c.

\subsection{Monte Carlo thermal mixing model sensitivity}

In order to examine the sensitivity of the parameters of the Monte Carlo thermal mixing model in (4), we vary groundwater discharge, groundwater temperature, culverted tributary temperature, and surface-heat exchange independently to determine the

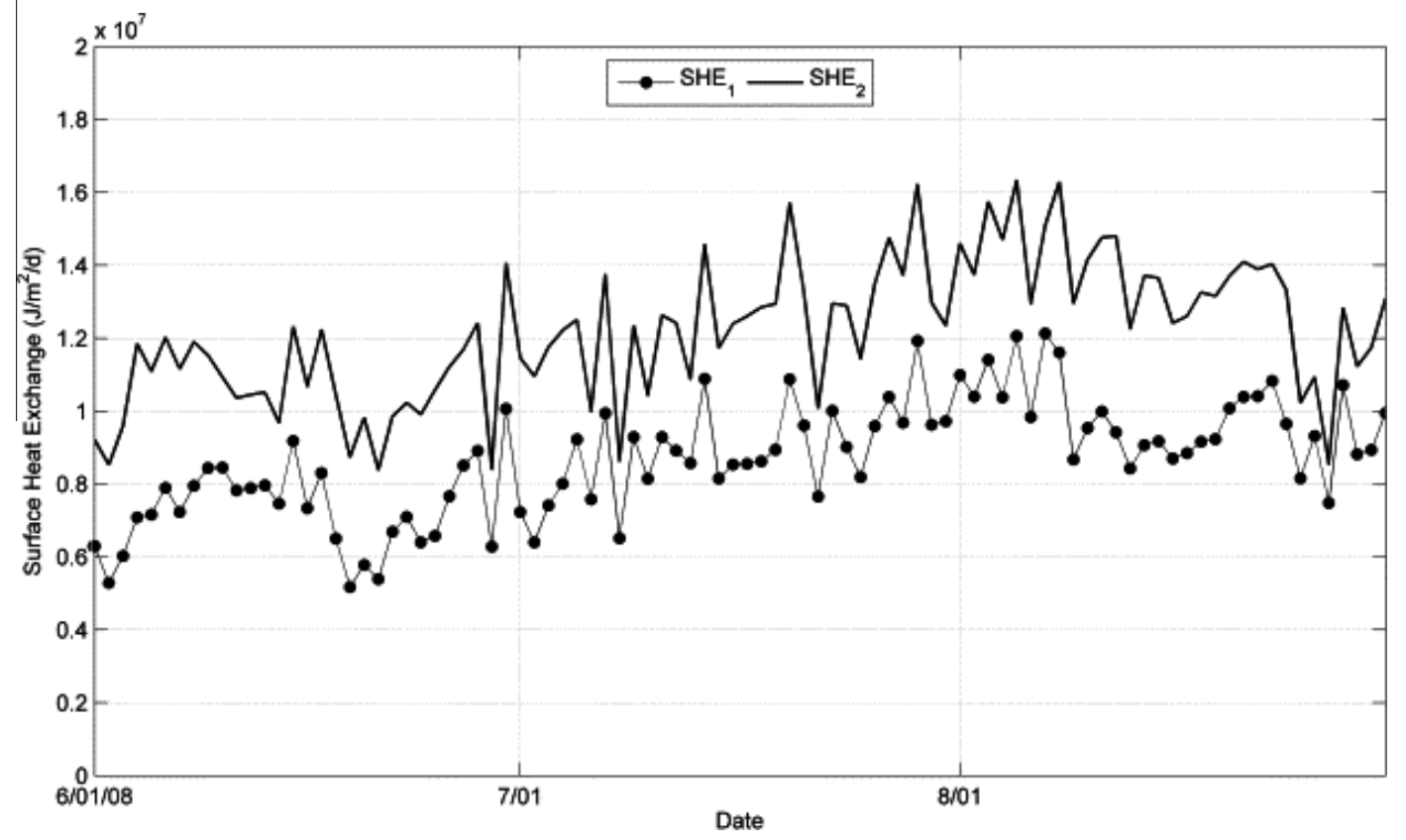

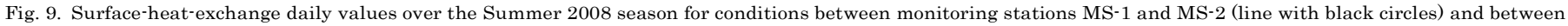
monitoring stations MS-3 and MS-4 (thick black line). 

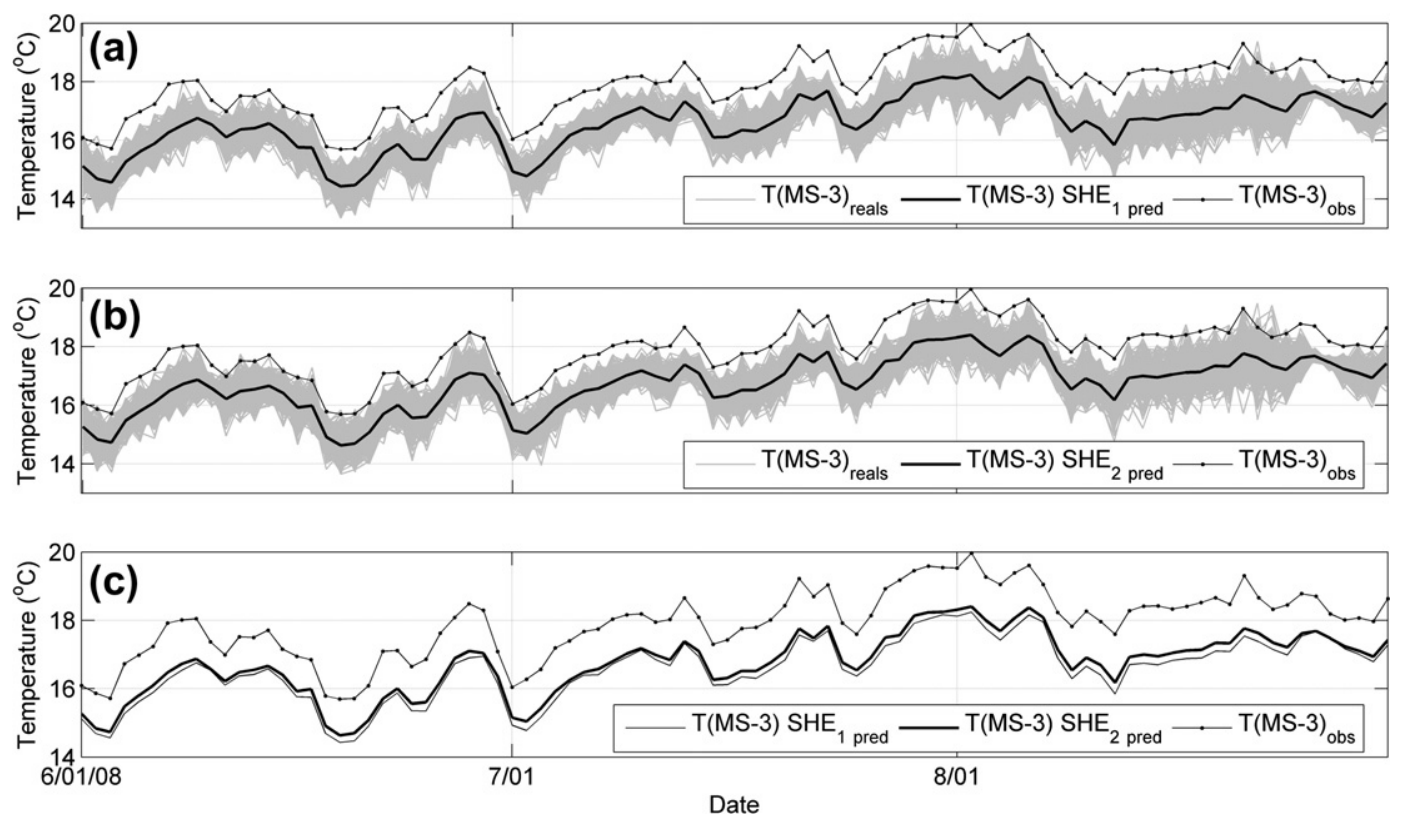

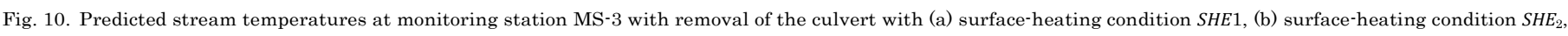

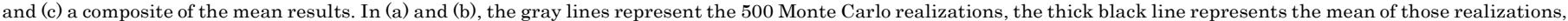

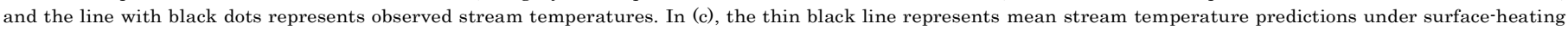
condition $S H E_{1}$, and the thick black line represents mean stream temperature predictions under surface-heating condition $S H E_{2}$.

influence of each of these parameters on predicted stream temperatures at monitoring station MS-3 (Table 2). In reporting the sensitivity results in the paragraphs that follow, we describe the variation between predicted stream temperatures at monitoring station MS-3 as mean, maximum, and minimum ranges between the two sensitivity simulations for each physical parameter. In all four sensitivity cases we vary the physical parameters over a defensible range. For example, in looking at the sensitivity of predicted temperatures to variations in baseflow rates, we utilize the statistics of our groundwater discharge velocity calculations and vary this parameter by two standard deviations of the daily data rather than arbitrarily raising and lower it by an order of magnitude.

Fig. 11a shows thermal mixing model sensitivity to baseflow rates. We vary the groundwater discharge velocities in these simulations by increasing and decreasing these components of the Monte Carlo thermal mixing model by two standard deviations of the modeled values. We do this in order to examine the influ-ence of the heterogeneity of the streambed materials. While we have sampled streambed temperatures at 15 locations in order to incorporate the highly-variable nature of the hydraulic properties of the streambed into our calculations, our randomly-chosen, discrete sampling locations may still not encompass the entire range of baseflow rates. The sensitivity calculations that we perform with varied baseflow rates show the influence of the uncertainty on predicted temperatures. The mean, maximum, and minimum temperature ranges for baseflow variations are $0.79^{\circ} \mathrm{C}, 1.46^{\circ} \mathrm{C}$, and $0.20^{\circ}$ $\mathrm{C}$, respectively. Groundwater temperatures are much less influential (Fig. 11b). We increase and decrease our base groundwater temperature of $10.6-12^{\circ} \mathrm{C}$ and $9^{\circ} \mathrm{C}$, respectively. Mean, maximum, and minimum temperature ranges are $0.30{ }^{\circ} \mathrm{C}, 0.45{ }^{\circ} \mathrm{C}$, and $0.05{ }^{\circ} \mathrm{C}$, respectively, under this sensitivity scenario.

Culverted tributary temperature variations show only slightly more sensitivity than groundwater temperature variations (Fig. 11c). The tributary stream joins Boone Creek within the culverted section and its discharging temperature is unknown. The Monte Carlo thermal mixing model discussed in the last section sets the tributary's temperature equivalent to stream temperatures measured at MS-2; however, because of the uncertainty in this value, sensitivity simulations vary the tributary temperature by $\pm 2.0^{\circ}$ C. Even with this rather large temperature variation, mean, maximum, and minimum temperature ranges are $0.50{ }^{\circ} \mathrm{C}, 0.82{ }^{\circ} \mathrm{C}$, and $0.03{ }^{\circ} \mathrm{C}$, respectively, under this sensitivity scenario. Fig. 11d shows model sensitivity to changes in $S H E_{1}$, which was doubled and halved for the sensitivity analysis. The predicted mean, maximum, and minimum temperature ranges for this parameter are $0.65^{\circ} \mathrm{C}, 1.09^{\circ} \mathrm{C}$, and $0.12{ }^{\circ} \mathrm{C}$, respectively.

We find with the sensitivity analysis that the two most sensitive parameters are baseflow rate and surface heating, with mean temperature decreases from measured values at monitoring station MS-3 of $0.92{ }^{\circ} \mathrm{C}$ and $0.91{ }^{\circ} \mathrm{C}$, respectively, even with the maximum influence of these parameters. The least sensitive parameter is groundwater temperature, where, when utilizing a groundwater temperature of $12{ }^{\circ} \mathrm{C}$, we predict a mean decrease in stream temperatures at monitoring station MS-3 of $1.20^{\circ} \mathrm{C}$. The sensitivity of predicted stream temperatures at monitoring station MS-3 to an increase in the culverted tributary temperature of $2{ }^{\circ} \mathrm{C}$ falls between the other sensitivity results, with a mean decrease of $1.10^{\circ} \mathrm{C}$ from measured values. Although sensitivity varies among the four physical parameters, the highest stream temperatures predicted with the sensitivity analyses all show a decline from observed stream temperatures; therefore, we are confident that the removal of the culvert will result in lower stream temperatures.

\subsection{Discussion of the Monte Carlo thermal mixing model}

In the previous section we show sensitivity analyses suggesting that surface-heat exchange and baseflow are the two most sensitive components of the Monte Carlo thermal mixing model. Another way of analyzing the relative influence of each parameter is through the analysis of each of the components of Eq. (4): (1) stream inflow based on $Q_{\mathrm{MS}-2}$ and $T_{\mathrm{MS}-2} ;(2)$ culverted tributary inflow based on $Q_{\text {trib }}$ and $T_{\mathrm{MS}-2}$; (3) surface-heat exchange based on $S H E_{1}$ and $S H E_{2}$; and (4) groundwater discharge to the restored stream based on $Q_{g w}$ and $T_{g w}$. By dividing each component of Eq. 

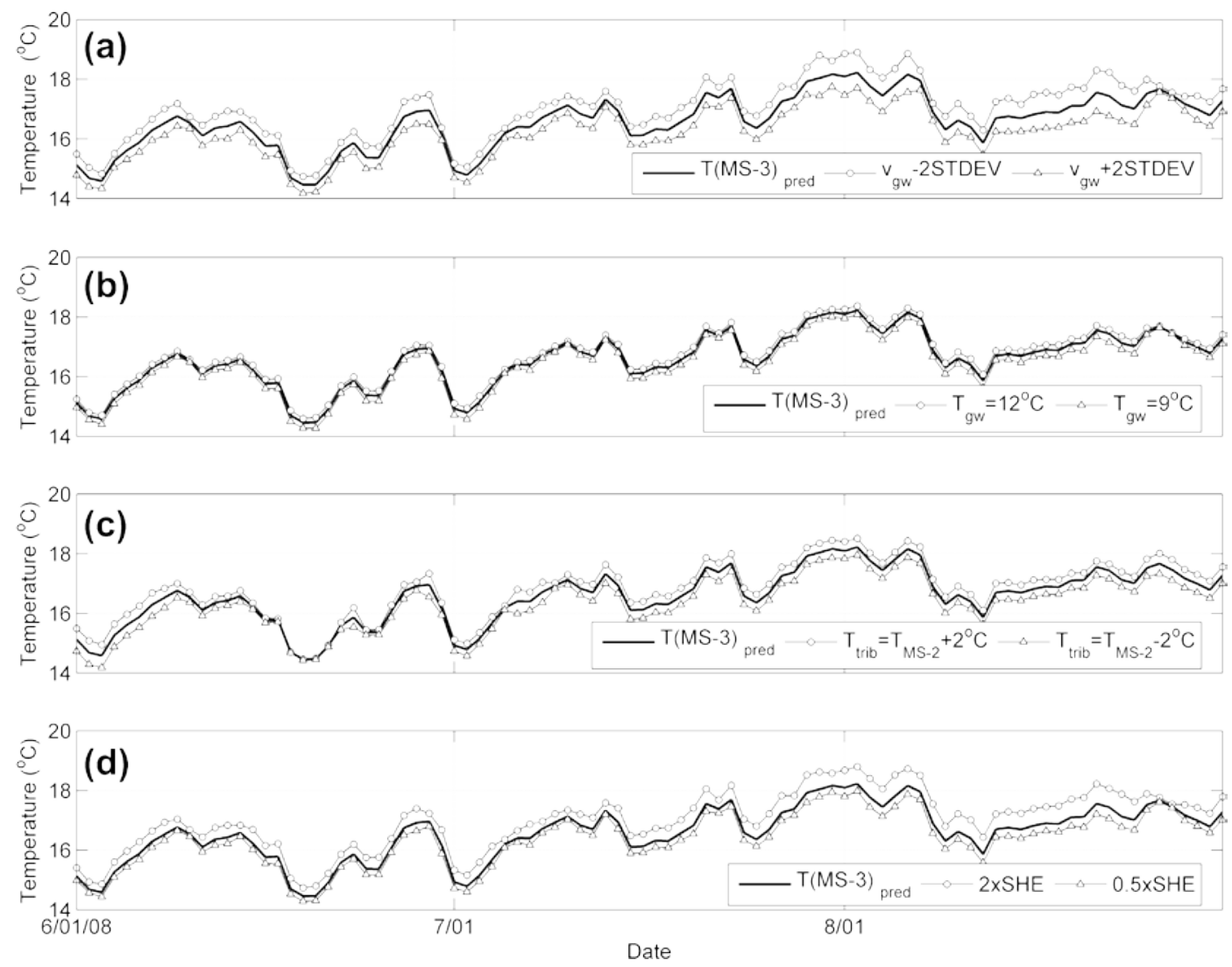

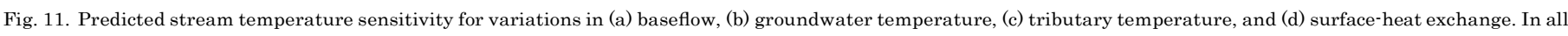

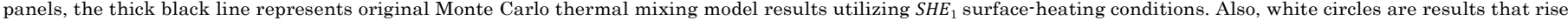
above the original simulation values, and white triangles are results that fall below the original simulation values.

(4) by the right-hand side, we can calculate the relative thermal contribution of each component in terms of temperature.

Under existing stream conditions, inflow at monitoring station MS-2 makes up $83.8 \%$ of stream discharge. The high component of flow coming into the study reach provides a high thermal inertia that has the strongest effect on downstream temperatures. The remaining discharge comprises $13.4 \%$ from the culverted tributary and $2.8 \%$ from baseflow. Baseflow constitutes a relative small percentage of the total flow because, with the existence of the culvert, only $210 \mathrm{~m}$ of the $920 \mathrm{~m}$ distance between monitoring stations MS2 and MS-3 receive groundwater discharge. The same is true for surface-heat exchange, in which only $210 \mathrm{~m}$ is available for direct interaction. The measured downstream temperature comprises components from each of these parameters. The bulk of the downstream temperature comes from surface discharge at monitoring station MS-2, which contributes a mean of $13.85{ }^{\circ} \mathrm{C}$ over the course of the monitoring data. Discharge from the culverted tributary also contributes a relatively high amount of heat at a temperature of $2.23{ }^{\circ} \mathrm{C}$. Due to their small area of interaction, surface-heat exchange and baseflow contribute very minimally to the existing stream temperatures at $0.20^{\circ} \mathrm{C}$ and $0.30{ }^{\circ} \mathrm{C}$, respectively. It should be noted that the temperature component of surface-heat exchange shown here does not take into account the influence of this parameter within the existing culvert.

Restoration of the stream will change the contributions of surface-heat exchange and baseflow by more than a factor of three. Stream discharge will increase under restored conditions with the addition of baseflow over the $700 \mathrm{~m}$ culvert's length. Modified mean stream discharge components under restored conditions include $77.6 \%$ from stream inflow at monitoring station MS-2, $12.4 \%$ from inflow at the culverted tributary, and $10.1 \%$ from restored baseflow conditions. Restored baseflow increases the influence of groundwater discharge over the studied stream reach by a factor of 3.6. The low groundwater temperature of $10.6{ }^{\circ} \mathrm{C}$ buffers stream temperatures downstream of the restoration by decreasing the relative influence of the warmer stream and culverted tributary discharges. Stream and culverted tributary contributions to the downstream temperature under restored conditions have decreased to $12.82{ }^{\circ} \mathrm{C}$ and $2.06{ }^{\circ} \mathrm{C}$, respectively. The groundwater discharge component increases to $1.07{ }^{\circ} \mathrm{C}$ under restored conditions because the higher baseflow component contributes more total heat to the system; however, stream temperatures under restored conditions still decrease by the values mentioned above due to the buffering of baseflow. Surface-heat exchange due to the restored connection between the atmosphere and the stream along the restored length also exerts more influence under restored conditions. The surface-heat exchange contribution to the restored downstream temperature rises $0.62{ }^{\circ} \mathrm{C}$ and $0.80{ }^{\circ} \mathrm{C}$ under upstream $\left(S H E_{1}\right)$ and downstream $\left(S H E_{2}\right)$ conditions, respectively. This is an increase in the influence of surface-heat exchange of between a factor of three to four above the existing stream conditions.

As was discussed in the previous section, sensitivity analyses were performed by varying the various parameters of the mixing model over an expected range of uncertainty. Fig. 11 shows that over these ranges the largest changes occur with variations in groundwater discharge rates and the level of surface-heat exchange. We find that doubling and halving the groundwater contribution increases and decreases the groundwater component of Eq. (4) by $0.85^{\circ} \mathrm{C}$ and $0.51{ }^{\circ} \mathrm{C}$, respectively, or a total range of $1.36{ }^{\circ} \mathrm{C}$. Of comparable magnitude are changes in surface-heat exchange, 
where doubling and halving of this parameter increases and decreases the surface-heat exchange component of Eq. (4) by $0.62{ }^{\circ} \mathrm{C}$ and $0.31{ }^{\circ} \mathrm{C}$, respectively, or a total range of $0.93{ }^{\circ} \mathrm{C}$. Culverted tributary and groundwater temperature components of Eq. (4) show much lower variability within an expected range of temperatures. Raising and lowering the culverted tributary temperature by $2{ }^{\circ} \mathrm{C}$ produces a change of $\pm 0.25{ }^{\circ} \mathrm{C}$, or a total of $0.50{ }^{\circ} \mathrm{C}$; raising and lowering the groundwater temperature by approximately $1.5^{\circ} \mathrm{C}$ produces a change of approximately $\pm 0.15^{\circ} \mathrm{C}$, or a total range of $0.30^{\circ} \mathrm{C}$.

\section{Conclusions}

The goal of this study has been to assess the effects of culvert removal on stream temperatures downstream of a hypothetical stream restoration. The study has utilized a thermal energy balance mixing model that balances inflowing stream conditions (stream discharge and temperature) with surface-heat exchange, restored groundwater conditions (groundwater discharge and temperature), and culverted tributary conditions (discharge and estimated temperature). The modeling study demonstrates that in streams containing a large baseflow component, the restoration of groundwater discharge to a previously culverted stream will buffer stream temperatures and will likely lower stream temperatures during the summer months. While the baseflow component of stream discharge along the study reach is only $3 \%$ of total stream discharge under existing conditions, the predicted effects of restoration will bring baseflow up to $10 \%$ of stream discharge. It is under these conditions that baseflow will have a strong buffering capability.

We have estimated two components of this model based on stream and streambed temperature measurements. Surface-heat exchange has been estimated upstream and downstream of the culvert due to land cover variations that include (1) riparian cover upstream of the culvert and (2) a lack of riparian cover downstream of the culvert. Daily surface-heat exchange values have been based on a thermal energy balance model (Becker et al., 2004) that utilized observed and estimated stream discharge and observed stream temperatures between two monitoring stations a known distance apart. Groundwater discharge rates have been estimated from 15 piezometer nests in which streambed temperatures have been measured. The dampening of the amplitude between streambed temperature time series measured a known distance apart has been used to estimate daily-mean groundwater discharge velocities (Hatch et al., 2006). These data have subsequently been sampled randomly from daily means and standard deviations of the groundwater discharge velocity field using a Monte Carlo method in order to estimate the range of potential variability in the predicted stream temperatures under restored conditions. Culverted tributary discharge and temperatures have been estimated from observed data and predicted groundwater discharge rates.

The results of the Monte Carlo thermal mixing model suggest that under both surface-heat exchange conditions used in this study, stream temperatures in a hypothetically restored stream will decrease from existing conditions with removal of a long culvert. In calculations using surface-heat exchange conditions estimated from current upstream riparian cover, stream temperatures will likely decrease by a mean of $1.35{ }^{\circ} \mathrm{C}$ with removal of the existing culvert. Stream temperatures will likely decrease by approximately $1.17^{\circ} \mathrm{C}$ with stream restoration under surface-heat exchange conditions estimated from current riparian cover downstream of the existing culvert. The results of this study have important implications to stream restoration projects in gaining streams. While projects are often pushed forward with the aim of restoring stream habitat, it is seldom that improved stream temperature regimes are cited as a reason for the restoration project. The Monte Carlo thermal mixing model utilized in this study, however, suggests that in baseflow-dominated streams, especially those in urban settings, improved stream temperatures may be an added benefit.

\section{Acknowledgements}

This manuscript benefitted from the detailed comments of three anonymous reviewers. We would like to thank them for investing the time and energy into helping us improve the manuscript. We would like to thank Appalachian State University and our departments for funding this study and Dr. Richard McLaughlin of the North Carolina State University Department of Soil Science for providing field equipment that was used in a portion of the study. Finally, we would like to thank Rachel Storniolo, Anna George Hazen, Carla Penders, and Blake Clark for their help with field work.

\section{References}

Anderson, M.P., 2005. Heat as a ground water tracer. Ground water 43, 951-968. doi:10.1111/j.1745-6584 2005.00052x.

Anderson Jr., W.P., Babyak, C.M., Thaxton, C.S., 2007. Baseline monitoring case study of a high-gradient urbanized stream: Boone Creek, Boone, NC. In: Proceedings of the 2nd National Low Impact Development Conference, Wilmington, NC, March 2007.

Becker, M.W., Georgian, R., Ambrose, H., Siniscalchi, J., Fredrick, K., 2004. Estimating flow and flux of ground water discharge using water temperature and velocity. Journal of Hydrology 296, 221-233.

Bogan, T., Mohseni, O., Stefan, H.G., 2003. Stream temperature-equilibrium temperature relationship. Water Resources Research 39(9). doi:10.1029/ 2003WR002034.

Bogan, T., Othmer, J., Mohseni, O., Stefan, H.G., 2006. Estimating extreme stream temperatures by the standard deviate method. Journal of Hydrology 317, 173189. doi:10.1016/j.jhydrol.2005.05.016.

Caissie, D., El-Jabi, N., St-Hilaire, A., 1998. Stochastic modeling of water temperatures in a small stream using air to water relations. Canadian Journal of Civil Engineering 25, 250-260.

Caissie, D., El-Jabi, N., Satish, M.G., 2001. Modelling of maximum daily water temperatures in a small stream using air temperatures. Journal of Hydrology $251,14-28$.

Caissie, D., Satish, M.G., El-Jabi, N., 2005. Predicting river water temperatures using the equilibrium temperature concept with application on Miramichi River catchments (New Brunswick, Canada). Hydrological Processes 19, 2137-2159. doi:10.1002/hyp. 5684

Caissie, D., Satish, M.G., El-Jabi, N., 2007. Predicting water temperatures using a deterministic model: application on Miramichi River catchments (New Brunswick, Canada). Journal of Hydrology 336, 303-315. doi:10.1016/ j.jhydrol.2007.01.008.

Conant, B.J., 2004. Delineating and quantifying ground water discharge zones using streambed temperature. Ground water 42, 243-257.

Fanelli, R.M., Lautz, L.K., 2008. Patterns of water, heat, and solute flux through streambeds around small dams. Ground Water 46, 671-687. doi:10.1111/ j.1745-6584.2008.00461.x.

Hatch, C.E., Fisher, A.T., Revenaugh, J.S., Constantz, J., Ruehl, C., 2006. Quantifying surface water-groundwater interactions using time series analysis of streambed thermal records: method development. Water Resources Research 42, W10410. doi:10.1029/2005WR004787.

Herb, W.R., Janke, B., Mohseni, O., Stefan, H.G., 2008. Thermal pollution of streams by runoff from paved surfaces. Hydrological Processes 22, 987-999. doi:10.1002/hyp. 6986.

Keery, J., Binley, A., Crook, N., Smith, J.W.N., 2007. Temporal and spatial variability of groundwater-surface water fluxes: development and application of an analytical method using temperature time series. Journal of Hydrology 336, 116. doi:10.1016/j.jhydrol.2006.12.003.

Lautz, L.K., 2010. Impacts of nonideal field conditions on vertical water velocity estimates from streambed temperature time series. Water Resources Research 46, W01509.

LeBlanc, R.T., Brown, R.D., FitzGibbon, J.E., 1997. Modeling the effects of land use change on the water temperature in unregulated urban streams. Journal of Environmental Management 49, 445-469.

Mohseni, O., Stefan, H.G., 1999. Stream temperature/air temperature relationship: a physical interpretation. Journal of Hydrology 218, 128-141.

Nelson, K.C., Palmer, M.A., 2007. Stream temperature surges under urbanization and climate change: data, models, and responses. Journal of the American Water Resources Association 43 (2), 440-452. doi:10.1111/j.1752-1688.2007.00034.x. 
O’Driscoll, M.A., DeWalle, D.R., 2006. Stream-air temperature relations to classify stream-ground water interactions in a karst setting, central Pennsylvania, USA. Journal of Hydrology 329, 140-153. doi:10.1016/j.jhydrol.2006.02.010.

Schmidt, C., Conant, B.J., Bayer-Raich, M., Schirmer, M., 2007. Evaluation and fieldscale application of an analytical method to quantify groundwater discharge using mapped streambed temperatures. Journal of Hydrology 347, 292-307. doi:10.1016/j.jhydrol.2007.08.022.
Sinokrot, B.A., Stefan, H.G., 1993. Stream temperature dynamics: measurements and modeling. Water Resources Research 29 (7), 2299-2312.

Webb, B.W., Hannah, D.M., Moore, R.D., Brown, L.E., Nobilis, F., 2008. Recent advances in stream and river temperature research. Hydrological Processes 22, 902-918. doi:10.1002/hyp. 6994. 